\title{
University Students' Self-Rated Ability to Interpret Social Context and Correlating Factors
}

\author{
Mika Kobayashi1,2, Naoko Fukuda', Kanako Ichikura ${ }^{3}$, Takashi Asakura² \\ ${ }^{1}$ Tokyo University of Marine Science and Technology (Etchujima Campus) Health Service Center, Tokyo, Japan \\ ${ }^{2}$ Laboratory of Health and Social Behavior, Tokyo Gakugei University, Tokyo, Japan \\ ${ }^{3}$ Department of Health Science, School of Allied Health Sciences, Kitasato University, Tokyo, Japan \\ Email:mkobayashi88@gmail.com,nfukuda@kaiyodai.ac.jp, asakurat@u-gakugei.ac.jp, ichikura-creha@umin.ac.jp
}

How to cite this paper: Kobayashi, M., Fukuda, N., Ichikura, K., \& Asakura, T. (2018). University Students' Self-Rated Ability to Interpret Social Context and Correlating Factors. Psychology, 9, 1546-1557. https://doi.org/10.4236/psych.2018.96093

Received: April 13, 2018

Accepted: June 26, 2018

Published: June 29, 2018

Copyright (c) 2018 by authors and Scientific Research Publishing Inc. This work is licensed under the Creative Commons Attribution International License (CC BY 4.0).

http://creativecommons.org/licenses/by/4.0/

(c) (i) Open Access

\begin{abstract}
Negative self-assessment of one's ability to interpret social context has been linked to psychological distress, manifesting as anxiety and depression. Few studies, however, have examined what individual skills and traits are present in those who score highly in self-assessments of their ability to interpret social context. Because Japanese culture places a high value on the collective good and one's ability to adapt one's behavior to a situation, this study also added the variable of the collective good to better understand factors associated with positive self-assessments of contextual awareness. This study was conducted at two universities, involving 603 students, and used self-completed anonymous questionnaires as well as a Revised Self-Monitoring scale, a Yamaguchi's Collectivism Scale, and self-rated ability to interpret social context while attending a class. The results and implications of this study include the finding that self-monitoring skills may be acquired, rather than viewed as innate traits, which could allow individuals to work toward better social adjustment through developing improved contextual awareness skills.
\end{abstract}

\section{Keywords}

Contextual Awareness, Interpreting Social Context, Self-Monitoring

\section{Introduction}

\subsection{The Importance of Contextual Awareness}

Contextual awareness, defined as "inferring an understanding of a particular situation from the context or social environment and adapting one's behavior to 
suit the situation" (Saito, 2007; Tanaka \& Miyamae, 2010), is a crucial component in university students' social lives and is highly valued in Japanese traditional culture. Recent research in Japan has probed the reasons for the recent increase in the number of people unable to "read" or interpret social context and who are thus lacking in contextual awareness (Aikawa \& Tomita, 2007).

\subsection{The Importance of Positive Self-Assessment Regarding Contextual Awareness}

A relationship between a negative self-assessment of social competence and psychological distress has been established in prior studies (Bédard, Bouffard, \& Pansu, 2014; Gable \& Shean, 2000), which revealed that negative self-assessments such as "I may not be able to interpret social context" are associated with psychological distress. Additionally, research shows that young adults in Japan are strongly defensive toward being set apart from their peers, in either real or perceived social isolation (Yoshida, 2003). Thus, it is reasonable that research has also shown that self-assessment indicating a lack of contextual awareness may contribute to anxiety and depression. Accordingly, a positive self-assessment of one's ability to interpret social context is important for mental health.

Few studies, however, have examined what individual skills are present in those who score highly in self-assessments of contextual awareness. In a preliminary study, self-monitoring, defined as "a personality trait that makes individuals pay attention to social situations so that they can change their behaviors to fit the situations," was strongly related to a positive self-assessment of contextual awareness (Fukuda, Kobayashi, Komuro, Wakisaka, \& Asakura, 2011). That study had two significant limitations. First, the sample size was small and unrepresentative of the general population, as it primarily consisted of young men at a single university, and second, it examined only the association between self-rated contextual awareness values and self-monitoring skills, with no other variables included as controls.

\subsection{Aims of the Current Study}

This study examined the relationships among self-assessment of contextual awareness, self-monitoring, and the collective good among university students. In Japan, a high value is placed on the collective good, or on putting group aims ahead of individual aims; thus, in the present study, the collective good was added as a value to the model to better understand what skills or characteristics are associated with positive self-assessments of contextual awareness.

\section{Methods}

The study was conducted in April and October 2011 at two national universities (A university and B university), involving 703 undergraduate students as participants. The authors hypothesized that contextual awareness may be different with regard to city size and college majors. Therefore, we chose two universities 
with distinctive features. A university is located in an urban area, whereas B university is located in a suburban area. Also, A university is a science university, specializing in marine and science technologies, whereas B university is a more generalized university with science and liberal arts majors. Students from the engineering department at A university and students from the literature department at B university participated in this study. The students were asked to fill out self-completed anonymous questionnaires that included four questions relating to demographic data (age, academic year, sex, and number of siblings), as well as a Revised Self-Monitoring (RSM) scale (11 items) and a Yamaguchi's Collectivism Scale (14 items), and to self-rate their ability to interpret social context while actively attending a class ( 2 items).

\subsection{The Revised Self-Monitoring Scale}

Self-monitoring was measured using the Japanese version of the Revised Self-Monitoring (RSM) scale, as originally developed by Lennox \& Wolfe (1984), and widely used (Fujioka \& Takahashi, 2008; Iwabuchi, Tanaka, \& Nakazato, 1982) as a reliable and valid measurement tool consisting of 11 items that measure two variables, namely: 1) the ability to modify self-presentation, and 2) sensitivity to the expressive behavior of others. Each item was assessed on a 6-point scale, with possible scores ranging from 6 to 30 for the ability to modify self-presentation and from 6 to 36 for sensitivity to the expressive behavior of others. Along this scale, the higher the score, the higher the level of ability related to each variable.

\subsection{The Yamaguchi's Collectivism Scale}

The Yamaguchi's Collectivism Scale was originally developed by Yamaguchi, Kuhlman, and Sugimori (1995) and consists of 14 items, with each item assessed on a 5-point Likert scale ranging from "describes me very well" to "does not describe me at all." Possible scores ranged from 14 to 70; the higher the score, the higher the level of the collective good. Items were introduced in Appendix.

\subsection{The Self-Rated Ability to Interpret Social Context}

After explaining the definition of "interpreting social context" to participants of the present study, we asked the following two questions: 1) How do you rate your ability to interpret social context? and 2) Would you like to change your ability to interpret social context? The first question was rated on a 5-point scale ranging from "cannot interpret social context at all" to "interpret social context too much," with the second question requiring a yes/no answer.

\subsection{Statistical Analyses}

This study examined the collected descriptive statistics on self-monitoring, the collective good, self-rated ability to interpret social context, and demographic data. Multivariate logistic regression was used to calculate odds ratios and 95 
percent confidence intervals to examine the association between participants' self-rated ability to interpret social context (or contextual awareness) and self-monitoring. The variables considered in the models were age, sex, number of siblings, Yamaguchi's Collectivism Scale metrics, and subscales of the RSM. All statistical analyses were performed using SPSS 18.0 for Windows (Japan IBM, Tokyo, Japan), with significance defined as $p<0.05$. Missing values in the variables which used for multivariate logistic regression (age, sex, the presence or absence of siblings, or Yamaguchi's Collectivism Scale, the RSM scale: the ability to modify self-presentation and sensitivity to the expressive behavior of others) were excluded for the analysis. The present study was designed in accordance with the principles of the Helsinki Declaration, and questionnaires were processed to assure anonymity, with a reply considered as consent to participate. This study was approved by the Ethics Committee of Tokyo Gakugei University on April 4, 2011 (\#32).

\section{Results and Discussion}

Demographic data and the average questionnaire scores are summarized in Table 1 , revealing that the response rate was 85.5 percent (603 students), average age was 20.5, and 78.9 percent (476 students) were male. Eighty students (13.3 percent) were from one-child families, while 523 students had siblings. Table 2 shows the rates of participants' self-rated ability to interpret social context; for example, 3.2 percent responded with "cannot interpret social context at all"

Table 1. Demographic data and average scores of the questionnaires.

\begin{tabular}{|c|c|c|c|}
\hline & & $\mathrm{n}$ & $\%$ \\
\hline \multicolumn{4}{|c|}{ Institutions } \\
\hline & A university & 532 & 88.2 \\
\hline & B university & 71 & 11.8 \\
\hline \multicolumn{4}{|l|}{ Sex } \\
\hline & Male & 476 & 78.9 \\
\hline & Female & 127 & 21.1 \\
\hline \multicolumn{4}{|c|}{ Siblings } \\
\hline & No & 80 & 13.3 \\
\hline & Yes & 523 & 86.7 \\
\hline \multicolumn{4}{|c|}{ Mean \pm SD } \\
\hline Age & & & $20.5 \pm 3.0$ \\
\hline \multicolumn{4}{|c|}{ Revised Self-Monitoring (RSM) scale } \\
\hline & elf-presentation & & $19.2 \pm 3.1$ \\
\hline & ssive behavior of others & & $22.0 \pm 5.9$ \\
\hline \multicolumn{4}{|c|}{ Yamaguchi's Collectivism Scale } \\
\hline & ctivism Scale & & $42.3 \pm 5.9$ \\
\hline
\end{tabular}


Table 2. Self-rated abilities to interpret social context.

\begin{tabular}{llc}
\hline & & $\mathrm{N}(\%)$ \\
\hline $\begin{array}{l}\text { 1) How do you rate your ability to } \\
\text { interpret social context? }\end{array}$ & $\begin{array}{lc}\text { cannot interpret social context at all (G1) } \\
\text { cannot interpret social context very well (G2) }\end{array}$ & 11 117(3.2\%) \\
& $\begin{array}{l}\text { can interpret social context a little (G3) } \\
\text { can interpret social context very well (G4) }\end{array}$ & $282(46.8 \%)$ \\
& interpret social context too much (G5) & $32(25.4 \%)$ \\
& & $32.3 \%)$ \\
$\begin{array}{l}\text { 2) Would you like to change your } \\
\text { ability to interpret social } \\
\text { context? }\end{array}$ & Yes & $181(30.3 \%)$ \\
& No & $417(69.7 \%)$
\end{tabular}

(G1), while 25.4 percent felt that they "can interpret social context very well" (G4). The most common response (at 46.8 percent) was "can interpret social context a little" (G3). Table 3 shows a cross-tabulation of the variables of participants' self-rated ability to interpret social context with the proportion of students that would like to change their self-rated ability to interpret social context.

The five groups were divided into two groups to conduct logistic regression analysis, namely: 1) G1 and G2; and 2) G3, G4 and G5. As shown in Table 4, the self-rated ability to interpret social context was not related to age, sex, the presence or absence of siblings, or Yamaguchi's Collectivism Scale; however, it was significantly related to the subscales of the RSM scale: the ability to modify self-presentation and sensitivity to the expressive behavior of others (OR 1.09, 95 percent CI 1.00 - 1.18; OR 1.11, 95 percent CI 1.05 - 1.18) (Table 4).

For a supplemental analysis, the five groups were then divided into three groups to conduct analysis of variance, with the RSM scale as dependent variable, namely: 1) G1 and G2;2) G3 and G4; and 3) G5. The results indicated a significant correlation with the RSM subscales (Table 5). Furthermore, a multiple comparison analysis indicated that G3 and G4 ("can interpret social context"), and G1 and G2 ("cannot interpret social context") were significantly different from one another, as were G5 ("interpret social context too much") and G1 and G2 ("cannot interpret social context").

\subsection{Summary of Findings}

This study used a cross-sectional design employing questionnaire surveys to reveal the relationships between university students' self-assessed ability to interpret social context, self-monitoring, and the collective good. The results demonstrated that the higher students scored on "ability to modify self-presentation" and "sensitivity to the expressive behavior of others," both sub-factors of self-monitoring, the more likely they were to positively assess themselves as able to interpret social context (Table 4, Table 5). This correlation was consistent with that of a similar pilot study, which suggested a relationship between self-monitoring and contextual awareness. Conversely, a relationship between the collective good and the self-assessed ability to interpret social context was 
Table 3. Cross-tabulation of two variables related to interpreting social context: "the self-rated ability" by "intention to change their ability".

\begin{tabular}{llll}
\hline & \multicolumn{2}{c}{$\begin{array}{c}\text { 2) Would you like to change your ability to } \\
\text { interpret social context? }\end{array}$} & \\
\hline & Yes (\%) & No (\%) & Total \\
\hline $\begin{array}{l}\text { 1) How do you rate your ability to interpret } \\
\text { social context? }\end{array}$ & & & \\
$\begin{array}{l}\text { Cannot interpret social context at all/cannot } \\
\text { interpret social context very well (G1, G2) }\end{array}$ & $66(49.3)$ & $68(50.7)$ & $134(100)$ \\
$\begin{array}{l}\text { Can interpret social context a little/can interpret } \\
\text { social context very well (G3, G4) }\end{array}$ & $101(23.4)$ & $331(76.6)$ & $432(100)$ \\
$\begin{array}{l}\text { Interpret social context too much (G5) } \\
\text { Total }\end{array}$ & $14(43.8)$ & $18(56.63)$ & $32(100)$ \\
\hline
\end{tabular}

Table 4. Logistic regression analysis: factors related to participants' self-related ability to interpret social context.

\begin{tabular}{|c|c|c|c|c|c|}
\hline \multirow{2}{*}{ Variables } & \multirow{2}{*}{ OR } & \multirow{2}{*}{ SE } & \multicolumn{2}{|c|}{$95 \% \mathrm{CI}$} & \multirow{2}{*}{$p$ value } \\
\hline & & & Lower & Upper & \\
\hline \multicolumn{6}{|l|}{ Demographic data } \\
\hline Age & 1.02 & 0.04 & 0.94 & 1.11 & 0.63 \\
\hline Sex & 0.89 & 0.27 & 0.52 & 1.50 & 0.65 \\
\hline Siblings (NO vs YES) & 1.11 & 0.31 & 0.60 & 2.04 & 0.75 \\
\hline \multicolumn{6}{|l|}{ Revised Self-monitoring (RSM) scale } \\
\hline Ability to modify self-presentation & 1.09 & 0.04 & 1.00 & 1.17 & 0.04 \\
\hline Sensitivity to expressive behavior of others & 1.11 & 0.03 & 1.05 & 1.18 & 0.00 \\
\hline \multicolumn{6}{|l|}{ Yamaguchi's Collectivism Scale } \\
\hline Yamaguchi's Collectivism Scale & 1.02 & 0.02 & 1.00 & 1.07 & 0.10 \\
\hline
\end{tabular}

$\mathrm{OR}=$ Odds Ratio, $\mathrm{SE}=$ Standard Error, $\mathrm{CI}=$ Confidence Interval.

Table 5. ANOVA: Difference in self-monitoring level between the degrees of interpreting social context.

\begin{tabular}{|c|c|c|c|c|c|}
\hline Variables & $\begin{array}{c}\text { Group A } \\
\mathrm{M} \pm \mathrm{SD}\end{array}$ & $\begin{array}{l}\text { Group B } \\
\mathrm{M} \pm \mathrm{SD}\end{array}$ & $\begin{array}{l}\text { Group C } \\
\mathrm{M} \pm \mathrm{SD}\end{array}$ & $p$ & $\begin{array}{l}\text { Tukey Multiple } \\
\text { Comparisons }\end{array}$ \\
\hline \multicolumn{6}{|l|}{ RSM scale } \\
\hline $\begin{array}{l}\text { Ability } \\
\text { to modify self-presentation }\end{array}$ & $17.9 \pm 3.2$ & $19.6 \pm 2.7$ & $19.4 \pm 5.5$ & 0.00 & Group A $<$ Group B, C \\
\hline $\begin{array}{l}\text { Sensitivity } \\
\text { to expressive behavior of }\end{array}$ & $19.6 \pm 4.9$ & $22.6 \pm 4.3$ & $23.5 \pm 5.7$ & 0.02 & Group A $<$ Group B, C \\
\hline
\end{tabular}

Group A = "cannot interpret social context" (G1, G2); Group B = "can interpret social context" (G3, G4); Group C = "interpret social context too much" (G5); RSM scale = Revised Self-monitoring scale; $\mathrm{M}=$ Mean, $\mathrm{SD}=$ Standard Difference.

not found (Table 4). Also, the results showed that people who indicated that they can interpret social context tend not want to change their ability to do so, 
unlike people who indicated that they cannot interpret social context and those who indicated that they interpret social context too much (Table 3). People who answered that they can interpret social context might satisfy their self-assessed ability to interpret social context and do not feel to change their abilities.

\subsection{Reasons for the Relationship between Self-Monitoring and the Self-Assessed Ability to Interpret Social Context}

In this study, self-monitoring and the self-assessed ability to interpret social context were considered to be related because they both require social skills intended for social adjustment. As stated, self-monitoring is defined as the ability to monitor whether or not one's behavior is socially appropriate and to modify said behavior accordingly (Snyder, 1974), and interpreting social context is a social skill involving speaking and behaving appropriately in accordance with the motivations and emotions of others (Hidaka \& Kosugi, 2012; Lau, Fung, Wang, \& Kang, 2009; Oishi, 2009). As such, both self-monitoring and self-assessment can be interpreted as behavioral traits for understanding a particular situation and practicing self-control based on a motivation to adjust oneself to society. Prior research has also indicated the possibility that, within some Asian cultures, assessing oneself as unable to interpret social context can trigger social anxiety (Lau et al., 2009). Japanese culture, for example, exerts particular pressure on members of a group who are different to either conform or risk exclusion (Morita \& Kiyonaga, 1994); additionally, Japanese people often associate being different with feelings of shame (Toda, 1997), and they are more likely than some other cultures to use expressions of self-deprecation to avoid being seen as different (Suzuki \& Yamagishi, 2004). In short, both self-monitoring (monitoring one's own behavior) and contextual awareness (understanding the motivations and emotions of others) among Japanese students can be interpreted as individual social behaviors that develop within a context of a uniquely Japanese pressure to conform in order to preserve harmony.

\subsection{Reasons for the Lack of Relationship between the Collective Good and Self-Assessment of Interpreting Social Context}

This study did not, however, demonstrate a relationship between the collective good and participants' self-assessed ability to interpret social context. This outcome is most likely due to the objective of interpreting social context among the Japanese university student participants not being related to the pursuit of group benefit. Modern Japanese students are likely to avoid confrontation or conflict with friends, often using contextual awareness as a means to prevent issues from arising (Doi, 2008). Japanese people's objective when interpreting social context has been seen as "unselfish" and "not assertive" (Hidaka \& Kosugi, 2012), and it may best be described as a passive motivation to avoid standing out in or being excluded from a group rather than as an active motivation to foster harmony. This avoidance of confrontation, however, can cause people to back down easily, leaving them unable to say no (Wada, 2007). This study also indicated that in- 
terpreting social context by Japanese students was not necessarily based on collective good reasoning.

\subsection{The Possibility of Clinical Applications}

As discussed in the introduction, assessing oneself as able to interpret social context has been linked to psychological health in university students. Taking into consideration the results of this study, being satisfied with one's ability to interpret social context appears more as a key factor to positive psychological health, rather than as a means to temporarily conform within a group. The clinical applications of these findings relate to the following considerations.

First, it is possible that strategies to improve skills related to interpreting social context will be themselves effective in creating satisfaction concerning one's contextual awareness. Given that this study revealed that self-monitoring and a self-assessed ability to interpret social context were related behavioral traits with shared objectives, attempting to improve self-monitoring skills may lead to improved psychological health. Additionally, the greater degree of self-monitoring occurring in adults may also be linked to working adults becoming accustomed to changes in their environment or becoming better adapted to corporate culture (Sato \& Shimizu, 2007; Tanaka \& Miyamae, 2010). Furthermore, although self-monitoring has been understood as an innate behavioral trait based on personality, it is possible that self-monitoring skills could also be acquired (e.g., based on environmental changes) (Day, Schleicher, Unckless, \& Hiller, 2002; Snyder, 1987). As for training related to social skills, individuals can work toward social adjustment through learning how to better understand the emotions and behavior of others and studying methods for adapting their behavior to the situation (Sato \& Sato, 2006). Through improving self-monitoring skills with social skills training, it may be possible to improve self-efficacy regarding the ability to interpret social context. Because previous research has also suggested that self-assessment and assessments from other people regarding self-monitoring tend to agree with one another (Snyder, 1987), it can be expected that improving self-monitoring skills would improve both self-evaluations and evaluations from others regarding the ability to interpret social context.

Second, it is possible that strategies to improve self-perceptions of one's ability to interpret social context are effective in creating satisfaction regarding contextual awareness. The results of this study also showed that interpreting social context included passive behaviors such as not being insistent in one's opinion. In these situations, simply behaving in reaction to external pressure to conform is unlikely to do more than bring about a temporary or situational adaptation, and does not contribute to long-term psychological health. In other words, people need to understand and accept their current skill levels and then work to improve any perceived weaknesses with a focus on long-term and autonomous psychological health, and not simply aim to become better at interpreting social context or engage in self-monitoring as short-term measures. For example, sup- 
portive psychotherapy uses techniques to promote self-acceptance, and cognitive therapy uses techniques to alleviate excessive self-criticism, meaning that counseling may be useful for university students who give themselves low assessments on their ability to interpret social context.

\section{Limitations}

This study is limited in three respects. First, although a sufficiently large sample size was achieved in comparison to the pilot study, the institutions where the surveys were conducted were limited to public universities; as such, this study was not sufficiently representative of Japanese university students. However, the participating institutions were strategically selected, involving one science-focused university located in an urban area and one liberal arts university in a small town. Second, the data for the present study was gathered during a medical checkup at A university and at a class lecture at B university. This might have made a difference in the participation rate.

Third, it is possible that using a self-administered scale to self-assess could have introduced bias. Generally, answers on self-administered scales can be easily influenced by perceptions of social desirability and, in this study, it is possible that it was difficult for participants to choose the answer "cannot interpret social context at all." Fourth, we cannot claim that the model used was completely effective, as this study only evaluated self-monitoring and the collective good as primary factors related to participants' self-assessed ability to interpret social context. It is possible that multiple other related factors are involved in interpreting social context.

\section{Conclusion}

Despite the limitations noted above, this study is likely to help in classifying the types of factors influencing university students' self-evaluation regarding their own contextual awareness. These results may also be valuable in that they demonstrate the culturally-based characteristics of social skills. It is recommended that in the future models be created that incorporate other values, such as self-efficacy, and that similar surveys be conducted in Western countries to assess the significance of cultural differences in understanding how social context is interpreted.

\section{Acknowledgements}

We would like to express our deepest appreciation to Dr. Sachi Tomokawa of Shinshu University for her assistance.

\section{References}

Aikawa, M., \& Tomita, T. (2007). Naze ima kukiga yomenai hitoga fueteirunoka (Why Have the Numbers of People Who Cannot Interpret Social Context Increased?). Nikkei Business Associé, Tokyo: Nikkei Business Publications, Inc. [In Japanese] 
Bédard, K., Bouffard, T., \& Pansu, P. (2014). The Risks for Adolescents of Negatively Biased Self-Evaluations of Social Competence: The Mediating Role of Social Support. Journal of Adolescence, 37, 787-98. https://doi.org/10.1016/j.adolescence.2014.05.004

Day, D. V, Schleicher, D. J., Unckless, A. L., \& Hiller, N. J. (2002). Self-Monitoring Personality at Work: A Meta-Analytic Investigation of Construct Validity. The Journal of Applied Psychology, 87, 390-401. https://doi.org/10.1037/0021-9010.87.2.390

Doi, T. (2008). Tomodachijigoku: "Kuki wo yomu" sedai no sabaibaru (Friendship Hell: The Survival of a Generation Interpreting Social Context). Tokyo: Chikuma Shobo. [In Japanese]

Fujioka, T., \& Takahashi, T. (2008). Revision of Lennox and Wolfe's Revised SelfMonitoring Scale. Journal of the Faculty of Education, Shinshu University, 120, 71-79. [In Japanese]

Fukuda, N., Kobayashi, M., Komuro, R., Wakisaka, K., \& Asakura, T. (2011). The Self-Related Inability to Interpret Social Context among College Students. Campus Health, 48, 133-138. [In Japanese]

Gable, S. L., \& Shean, G. D. (2000). Perceived Social Competence and Depression. Journal of Social and Personal Relationships, 17, 139-150. https://doi.org/10.1177/0265407500171007

Hidaka, M., \& Kosugi, K. (2012). An Empirical Study of the Expression "kuki wo yomu". Bulletin of the Faculty of Education, Yamaguchi University, 62, 139-144. [In Japanese]

Iwabuchi, C., Tanaka, K., \& Nakazato, H. (1982). A study of the Self-Monitoring Scale. The Japanese Journal of Psychology, 53, 54-57. [In Japanese] https://doi.org/10.4992/jjpsy.53.54

Kashima, Y., Yamaguchi S., \& Kim, U. et al. (1995) Culture, Gender, and Self: A Perspective from Individualism-Collectivism Research. Journal of Personality and Social Psychology, 69, 925-937. https://doi.org/10.1037/0022-3514.69.5.925

Lau, A. S., Fung, J., Wang, S., \& Kang, S.-M. (2009). Explaining Elevated Social Anxiety among Asian Americans: Emotional Attunement and a Cultural Double Bind. Cultural Diversity and Ethnic Minority Psychology, 15, 77-85. https://doi.org/10.1037/a0012819

Lennox, R., \& Wolfe, R. (1984). Revision of the Self-Monitoring Scale. Journal of Personality and Social Psychology, 46, 1349-1364. https://doi.org/10.1037/0022-3514.46.6.1349

Morita, Y., \& Kiyonaga, K. (1994). Ijime: Kyoshitsu no yamai (Bullying: The Issue within the Classroom). Tokyo: Kaneko Shobo. [In Japanese]

Oishi, C. (2009). What Does “Interpret Social Context" Mean?: An Approach to a Deficit of Social Skills. Bulletin of the Tokyo Women's College of Physical Education and Tokyo Women's Junior College of Physical Education, 44, 87-96. [In Japanese]

Saito, T. (2007). Ki no chikara: Ba no kuki wo yomu, nagare wo kaeru (The Power of Chi: Interpreting Social Context and Changing Direction). Bungeishunju. Tokyo: Bungeishunju Ltd. [In Japanese]

Sato, M., \& Shimizu, Y. (2007). Environmental Changes Caused by Corporate Mergers and the Psychological Adjustment of Employees. Annual Bulletin of Institute of Psychological Studies, Showa Women's University, 10, 42-53.

Sato, S., \& Sato, Y. (2006). Gakkoniokeru SST jissengaido: Kodomo no taijinsukirushido (The SST Practical Guideline in Schools: Interpersonal Skill Education for Children). Tokyo: Kongoshuppan Ltd.

Snyder, M. (1974). Self-Monitoring of Expressive Behavior. Journal of Personality and Social Psychology, 30, 526-537. https://doi.org/10.1037/h0037039 
Snyder, M. (1987). Public Appearances, Private Realities: The Psychology of Self-Monitoring. New York, NY: W. H. Freeman.

Suzuki, N., \& Yamagishi, T. (2004). An Experimental Study of Self-Effacement and Self-Enhancement among the Japanese. Japanese Journal of Social Psychology, 20, $17-25$.

Tanaka, K., \& Miyamae, J. (2010). The Interaction of Self-Affirmation to Other-Directedness and Social Support. Kagawadaigaku-Kyouikujissen-Sougoukenkyu, 20, 33-43.

Toda, Y. (1997). Bullying and/or Being Bullied Experiences, and Attitudes toward Bullying of Students in Faculties of Education. The Journal of the Faculty of Education, Tottori University, 6, 19-28.

Wada, H. (2007). "Ba no Kuki” wo yomunogajozunahitohetanahito (“Good or Poor Interpreters of Social Contexts”). Tokyo: Shinkosha Ltd.

Yamaguchi, S., Kuhlman, D., \& Sugimori, S. (1995). Personality Correlates of Allocentric Tendencies in Individualist and Collectivist Cultures. Journal of Cross-Cultural Psychology, 26, 658-672. https://doi.org/10.1177/002202219502600609

Yoshida, H. (2003). University Student Relationships: An Analysis of Questionnaire Surveys from Five Universities. Kawasaki Medical Welfare Journal, 13, 173-186. 


\section{Appendix: Yamaguchi's Collectivism Scale}

I. I don't sacrifice self-interest for my group

自分の友人集団のために自分の利益を犠牲にすることはない

2. I don't think it necessary to act as fellow group members would prefer

友人集団の仲間の望むように行動する必要はないと思う

3. I stick with my group even through difficulties

困難な状況にあっても自分の友人集団に留まる

4. I keep sum of my group

自分の友人集団の和を保っている

5. I don't change my opinions in conformity with those of the majority

多数の人の意見に合わせて、自分の意見を変えることはない

I don't support my group when they are wrong

6. 自分の友人集団が間違っているときには、その友人集団を支持しない

7. I respect decisions made by my group 自分の友人集団の決定を尊重する

8. I stick with my group if it its required even I feel dissatisfaction with my group

自分の友人集団に不満でも、必要とされればその友人集団に留まる

9. I assert my opposition when I disagree strongly with the members of my group

友人集団の仲間と非常に意見が違っているときは、仲間と反対の意見でも主張する

10. I often pretend to agree with the majority opinion in my group

友人集団の仲間と意見の不一致を生じないようにする

11. I blame my group when I feel they are wrong

自分の友人集団でも、間違っていると思ったら、それをとがめる

I would rather leave my group if I have to sacrifice my self-interest for the group

12. 自分の友人集団のために自分の利益を犠牲にしなければならないのならその友人集団 を離れた方がよい

13. I do things in my way regardless of what my group members expect me to do 友人集団の仲間がどう思抢うと、私は自分のやり方でものごとを行う

14. I stick to my opinions even when others in my group don't support me 友人集団の仲間に支持されなくても、自分の意見を变えない

${ }^{\star}$ In the present study, we used the original Japanese version of Yamaguchi's Collectiveness scale. This English version was made based on Yamaguchi, Kuhlman, and Sugimori (1995) and Kashima, Yamaguchi, Kim, et al. (1995). Items 4, 8, and 10 was translated from Japanese into English by authors in the present study. 